Article

\title{
Production of Nigella sativa Beverage Powder under Foam Mat Drying Using Egg Albumen as a Foaming Agent
}

\author{
Norhazirah Affandi ${ }^{1}$, Wahidu Zzaman ${ }^{1,2, *}$, Tajul Aris Yang ${ }^{1}$ and Azhar Mat Easa ${ }^{1}$ \\ 1 Food Technology Division, School of Industrial Technology, Universiti Sains Malaysia, Pulau Penang 11800, \\ Malaysia; hazirahaffandi@gmail.com (N.A.); taris@usm.my (T.A.Y.); azhar@usm.my (A.M.E.) \\ 2 Department of Food Engineering and Tea Technology, Shahjalal University of Science and Technology, \\ Sylhet 3114, Bangladesh \\ * Correspondence: wahidanft@yahoo.com or wahiduzzaman@usm.my; Tel.: +604-653-2224 \\ Academic Editor: Maja Benković
}

Received: 20 October 2016; Accepted: 17 January 2017; Published: 27 January 2017

\begin{abstract}
The aim of this study was to determine the feasibility of producing Nigella sativa powder under a foam mat drying technique. A central, composite design of experiments was used to optimize the drying condition and compare the solubility, the antioxidant and mineral content of roasted Nigella sativa, and the foam mat dried Nigella sativa powder. Foams were prepared from Nigella sativa solution by adding different concentrations of egg albumen $(2.5 \%, 8.75 \%$, and $15 \% \mathrm{w} / \mathrm{w})$ and methyl cellulose $(0,0.5 \%$ and $1 \% \mathrm{w} / \mathrm{w})$, using whipping times of 2,5 , and $8 \mathrm{~min}$. The drying temperature was set at $50-70{ }^{\circ} \mathrm{C}$, with a foam thickness of 1,2 , and $3 \mathrm{~mm}$. The optimum recorded conditions for the foaming process were $15 \%$ of egg albumen concentration, $0.69 \%$ of methyl cellulose concentration, and a whipping time of $8 \mathrm{~min}$. Thus, the optimum conditions for the drying process were $60^{\circ} \mathrm{C}$, with $2 \mathrm{~mm}$ of foam thickness. The results showed that there were significant differences in DPPH inhibition, the total phenolic content, and mineral content, whereas no significant differences were recorded in the water solubility index between the roasted Nigella sativa and the foam mat dried Nigella sativa powder.
\end{abstract}

Keywords: methyl cellulose; solubility; antioxidant; mineral content; central composite design

\section{Introduction}

The present study focuses on the production of an instant beverage powder. Instant beverage powder is a popular and convenient way for consumers to make their favorite drinks, by simply adding either hot or cold water. Drying is a unique method for producing powder forms of raw food materials. Drying can reduce the water activity, as the removal of water from the food's surface occurs during the drying process. This inhibits both microbial growth during storage, and undesirable enzymatic reactions, thus extending the shelf life of the food products. Moreover, drying can cause a reduction in the weight and volume of product, and this minimizes the product's packaging, storage, and transportation costs [1]. Drying involves both heat transfer and mass transfer, which refers to the removal of water. Heat can be transferred by conduction, convection, or radiation [2]. Many factors need to be considered when choosing a drying technique. These involve the characteristics of the food to be dried, the quality of the desired final product, and the processing costs to ensure a high quality dried product is obtained.

Several techniques, such as hot air drying, spray drying, drum drying, freeze drying, and foam mat drying, have been employed for the production of an instant beverage powder. Freeze drying and spray drying yield products of high quality, in terms of rehydration and color. However, these two 
processes require high operation and set-up costs [3,4]. Hot air drying is the simplest and cheapest drying method, but the quality of the dried product is fairly poor. Drum drying uses a high temperature and this causes an undesirable cooked aroma and a severe loss in the quality of the final product [5].

In this research, foam mat drying was used to make an instant beverage powder from Nigella sativa. Nigella sativa is a herbaceous plant that belongs to the Ranunculaceae plant family and it is commonly used as a food additive. According to Hasanah et al. [6], Nigella sativa powder solution is abundant in nutrients and antioxidants. Nigella sativa components include amino acids, proteins, carbohydrates, fixed oils, volatile oils, alkaloids, saponin, and fiber. Moreover, the powder also contains calcium, iron, potassium, and sodium. Since foam mat drying is simple, rapid, and uses a lower energy technique, it could be a better choice for drying the Nigella sativa, in order to preserve the nutrients.

Foam mat drying is a process during which the the transformation of products from a liquid state, to a stable foam, is followed by air drying. The process has advantages, such as a shorter drying time due to the honeycomb structure of the foam, which results in a quick removal of moisture from the food, thus reducing the nutritional losses. In addition, this method can be used to dehydrate high sugar content, heat-sensitive, sticky, and viscous food [7]. The other advantage associated with foam mat drying is the low cost operation, when compared to vacuum, freeze, and spray drying [8]. The foam mat drying method has been applied to many fruits and other food materials, such as mango pulp [9], papaya pulp [10], yogurt [11], Gac fruit aril [7], and banana [12]. The main objective was to make Nigella sativa powder and its ensure its quality. The study was pursued with the aim of optimizing the foam mat drying condition of the prepared solution from roasted seed and evaluating the solubility, and the antioxidant and mineral content, of the foam mat dried Nigella sativa powder.

\section{Materials and Methods}

\subsection{Preparation of Nigella sativa Foam}

Roasted Nigella sativa seeds were purchased from a factory (Sati \& Fuzi Trading Sdn. Bhd., Ipoh-31150, Perak, Malaysia). Approximately $10 \%(\mathrm{w} / \mathrm{v})$ of the Nigella sativa solution was prepared by blending the roasted Nigella sativa with $50{ }^{\circ} \mathrm{C}$ distilled water, which was then filtered to separate the solution and the impurities. The solution was sealed in a glass bottle and stored at room temperature for further study. Egg albumen (purchased from Sim Company, Pulau Pinang, Malaysia) and methyl cellulose (purchased from Sim Company, Pulau Pinang, Malaysia), were used as a foaming agent and a foam stabilizer, respectively. About $50 \mathrm{~mL}$ of Nigella sativa solution was poured into a mixing bowl. The solution, egg albumen $(2.5 \%, 8.75 \%$, and $15 \%)$, and methyl cellulose $(0,0.5 \%$, and $1 \%)$, were whipped using a hand blender (Philips HR1602 Hand blender, Amsterdam, Netherlands) at low speed, for different whipping times $(2,5$ and $8 \mathrm{~min})$. The foam was carefully transferred to a $250 \mathrm{~mL}$ measuring cylinder, ensuring that it did not collapse.

\subsection{Foaming Properties}

\subsubsection{Foam Density}

The Nigella sativa foam was transferred into the measuring cylinder without trapping the air voids or collapsing the foam structure. The weight and volume of the foam were recorded [13]. The foam density was determined using the following Equation (1):

$$
\text { Foam Density }=\frac{\text { Weight of foam, } \mathrm{g}}{\text { Volume of foam, } \mathrm{cm}^{3}}
$$




\subsubsection{Foam Expansion}

Foam expansion was calculated to determine the amount of air incorporated into the solution during whipping. It was calculated using the following equation, as described by [14]:

$$
\text { Foam expansion }(\%)=\left[\frac{V_{1}-V_{0}}{V_{0}}\right] \times 100
$$

where $V_{0}$ is the initial volume of Nigella sativa solution $\left(\mathrm{cm}^{3}\right)$ and $V_{1}$ is the final volume of foamed Nigella sativa $\left(\mathrm{cm}^{3}\right)$.

\subsubsection{Foam Stability}

The foam obtained was placed in a transparent graduated cylinder and kept at room temperature for $2 \mathrm{~h}$. The volume of liquid, which was separated from the foam as a result of drainage, and the reduction in foam volume, were measured. Foam stability was calculated using the following relationship, as described by [15]:

$$
\text { Foam stability }(\%)=\frac{V_{1}}{V_{0}} \times 100
$$

where $V_{1}$ is the volume of foam after $2 \mathrm{~h}\left(\mathrm{~cm}^{3}\right)$ and $V_{0}$ is the initial volume of foam $\left(\mathrm{cm}^{3}\right)$.

\subsection{Drying Properties}

The foamed Nigella sativa was prepared based on the optimized foaming parameters. The foam was then spread in a stainless steel tray $\left(21 \times 13 \times 4.25^{\prime \prime}\right)$ with different thicknesses $(1,2$, and $3 \mathrm{~mm}$ ), and subjected to hot air drying with different air temperatures of 50, 60, and $70{ }^{\circ} \mathrm{C}$ (Model: AMS-RXH-7-C, Zhengzhou, China) and a relative air humidity of $10 \%$, using a constant air velocity of $1.0 \mathrm{~m} / \mathrm{s}$. Drying was stopped when the weight of the samples reached constant values. The obtained powders had median diameters, in the range of 100 to 250 microns.

Dried foam was scraped from the tray, ground, packed in a plastic zipper bag, and stored at room temperature for quality determination.

\subsubsection{Moisture Content}

The moisture content of the foam mat dried Nigella sativa powder was determined using the method presented by [16], with slight modifications. Approximately $3 \mathrm{~g}$ of the powder was dried in the oven (Oven Memmert UM600, Apeldoorn, The Netherlands) at a temperature of $105^{\circ} \mathrm{C}$ for $4 \mathrm{~h}$. Thereafter, the sample was cooled in a desiccator and weighed. The weight loss after drying in the oven was used to calculate the moisture content of the powder and the result was expressed on a dry basis:

$$
\% \text { moisture }=\frac{W_{2}-W_{3}}{W_{2}-W_{1}} \times 100 \%
$$

where $W_{1}$ = weight of moisture dish, $W_{2}$ = weight of moisture dish and sample (wet), and $W_{3}=$ weight of moisture dish and sample (dry).

\subsubsection{Water Activity}

Water activity of the Nigella sativa powder was measured at $25^{\circ} \mathrm{C}$, using a water activity meter (AquaLab Model Series 3TE, Pullman, WA, USA).

\subsubsection{Water Solubility and Absorption Index}

Approximately $1 \mathrm{~g}$ of the Nigella sativa powder was added to $30 \mathrm{~mL}$ of water at $50{ }^{\circ} \mathrm{C}$ and shaken in a water bath for $30 \mathrm{~min}$. Following this, the mixture was centrifuged for $10 \mathrm{~min}$ at $3500 \mathrm{rpm}$. 
The supernatant was carefully transferred into a moisture dish and oven-dried overnight at $100{ }^{\circ} \mathrm{C}$. The weight of the solids in the dried supernatant, as a percentage of the total dry solids in the original $1 \mathrm{~g}$ of the sample, provides an indication of the solubility index [17]. The water absorption index was measured by noting the amount of wet solids remaining after centrifugation. The water solubility index (WSI) and water absorption index (WAI) were calculated using the following equations:

$$
\begin{aligned}
& \text { WSI }(\%)=\frac{\text { Weight of dry solids after centrifugation }}{\text { Weight of initial dry sample }} \times 100 \\
& \text { WAI }=\frac{\text { Weight of wet solid remaining after centrifugation }}{\text { Weight of initial dry sample }}
\end{aligned}
$$

\subsubsection{Colour}

A Minolta Spectrophotometer CM-3500 (Konica Minolta Co., Osaka, Japan) was used to measure the colour of the Nigella sativa powder. Calibration was performed prior to the measurement [17]. The instrument was calibrated with zero calibration (CM-A-100), followed by a white calibration plate (CM-A120). Parameters such as lightness $\left(L^{*}\right)$, redness $\left(a^{*}\right)$, and yellowness $\left(b^{*}\right)$ were determined.

\subsubsection{Bulk and Tapped Density}

The bulk and tapped density were determined according to the method presented in [18], with slight modifications. Bulk density was determined by placing $1 \mathrm{~g}$ of the Nigella sativa powder into a $10 \mathrm{~mL}$ granulated cylinder. The volume occupied by the powder was measured, without tapping the cylinder. The tapped density was determined by tapping the loaded cylinder 15 times from a height of $10 \mathrm{~cm}$, and the final volume was recorded. The bulk and tapped density were calculated using the following formulas:

$$
\begin{aligned}
& \text { Bulk Density }\left(\rho_{\mathrm{B}}\right)=\frac{\text { Mass of the Nigella sativa powder, } \mathrm{g}}{\text { Volume of the Nigella sativa powder, } \mathrm{cm}^{3}} \\
& \text { Tapped Density }\left(\rho_{\mathrm{T}}\right)=\frac{\text { Mass of the Nigella sativa powder, } \mathrm{g}}{\text { Final tapped volume, } \mathrm{cm}^{3}}
\end{aligned}
$$

\subsubsection{Experimental Design and Optimization}

A response surface methodology was applied to the experimental data using a statistical package (Design Expert version 6.0.10, 2003, Minneapolis, MN, USA), for the generation of response surface plots and optimization of the process variables [19]. Central Composite Design (CCD) was used to design the experiments of foaming and drying processes. In the foaming process, three factors with three levels were used, and 20 runs with different combinations were conducted. In the drying process, two factors with three levels were used, and a total of 13 runs of different combinations were conducted. The details of the experimental design used in the present study are given in Tables 1 and 2.

Table 1. Different levels of coded and uncoded variables for foaming process.

\begin{tabular}{cccccc}
\hline \multirow{2}{*}{ Factors } & \multirow{2}{*}{$\begin{array}{c}\text { Independent } \\
\text { Variables }\end{array}$} & Units & \multicolumn{3}{c}{ Levels } \\
\cline { 4 - 6 } & & & $\mathbf{- 1}$ & $\mathbf{0}$ & $\mathbf{+ 1}$ \\
\hline A1 & Egg albumen & $\%$ & 2.5 & 8.75 & 15 \\
B1 & Methyl cellulose & $\%$ & 0 & 0.5 & 1 \\
C1 & Whipping time & min & 2 & 5 & 8 \\
\hline
\end{tabular}


Table 2. Different levels of coded and uncoded variables for drying process.

\begin{tabular}{ccccccc}
\hline \multirow{2}{*}{ Factors } & \multirow{2}{*}{$\begin{array}{c}\text { Independent } \\
\text { Variables }\end{array}$} & Units & \multicolumn{3}{c}{ Levels } \\
\cline { 4 - 6 } & & & $\mathbf{- 1}$ & $\mathbf{0}$ & $\mathbf{+ 1}$ \\
\hline A1 & Drying temperature & ${ }^{\circ} \mathrm{C}$ & 50 & 60 & 70 \\
$\mathrm{~B} 1$ & Foam thickness & $\mathrm{mm}$ & 1 & 2 & 3 \\
\hline
\end{tabular}

\subsection{Chemical Analysis of the Nigella sativa Powder}

\subsubsection{Extraction of Sample}

The method employed for the extraction of the total phenolics content and antioxidants in the Nigella sativa powder samples, followed the method presented by [20], with slight modifications. About $0.25 \mathrm{~g}$ of dried sample was mixed with $10 \mathrm{~mL}$ of $70 \%$ methanol, for $1 \mathrm{~h}$ at $40{ }^{\circ} \mathrm{C}$ in a water bath shaker. The resulting mixture was centrifuged at $3500 \mathrm{rpm}$ for $15 \mathrm{~min}$, and the supernatant was then separated and used to investigate the total phenolics content and antioxidant activity assays.

\subsubsection{Determination of DPPH Free Radical-Scavenging Activity}

The free radical-scavenging activity of the extract was determined using 2,2-diphenyl-1picrylhydrazyl (DPPH) assay, following the method reported by [21], with some modifications. An aliquot of $300 \mu \mathrm{L}$ of the sample extract was added to $2 \mathrm{~mL}$ of DPPH (2.5 mg per $100 \mathrm{~mL}$ of $50 \%$ methanol). The mixture was kept in the dark for $30 \mathrm{~min}$. The absorbance was later measured at $515 \mathrm{~nm}$, using an ultraviolet-visible spectrophotometer. The result is represented as the percentage of inhibition of the DPPH radical, which was calculated according to the following equation:

$$
\text { Percentage of inhibition of DPPH }(\%)=\left[\frac{\text { Abs control }- \text { Abs sample }}{\text { Abs control }}\right] \times 100
$$

where Abs control is the absorbance of the control and Abs sample is the absorbance of the samples.

\subsubsection{Determination of Total Phenolic Content}

Total phenolic content was determined using Follin-Ciocalteu (FC) reagent, according to the procedure presented by [22], with some modifications. About $40 \mu \mathrm{L}$ of the sample extract was introduced into a test tube, followed by $200 \mu \mathrm{L}$ of Follin-Ciocalteu's reagent. The mixture was allowed to stand at room temperature for $5 \mathrm{~min}$. Following this, $600 \mu \mathrm{L}$ of $20 \%(\mathrm{w} / \mathrm{v})$ aqueous solution of sodium carbonate was added to the tube and mixed well. The mixture was incubated for $30 \mathrm{~min}$ at $40^{\circ} \mathrm{C}$. The absorbance of the sample was measured at $765 \mathrm{~nm}$, using an ultraviolet-visible spectrophotometer. A calibration curve was prepared using 80, 160, 240, 320, 400, and $480 \mathrm{mg} / \mathrm{L}$ solutions of gallic acid. The result was expressed as gallic acid equivalent in $\mathrm{mg}$ GAE/g.

\subsection{Determination of Minerals Content}

\subsubsection{Digestion of Sample}

For determining the mineral content in a sample using an Atomic Absorption Spectrometer (P.E.A Analyst 100, HGA-800 and MHS-10, Perkin Elmer, Waltham, MA, USA), the sample must first be digested. For digestion, $10 \mathrm{~mL}$ of nitric acid and $1 \mathrm{~mL}$ of hydrogen peroxide were added to $1 \mathrm{~g}$ of Nigella sativa powder in the sample vessel. Then, they were digested in a microwave digester for $55 \mathrm{~min}$ [23]. The mineral content was analyzed according to the method described for calcium, sodium, copper, iron, and manganese [3]. 


\section{Calcium}

First, $50 \mathrm{~mL}$ of deionized water was added to $58.64 \mathrm{~g}$ of lanthanum oxide, then $250 \mathrm{~mL}$ of hydrochloric acid was added, and the total mixture in the volumetric flask was $1 \mathrm{~L}$. Approximately $20 \mathrm{~mL}$ of lanthanum oxide was added to the digested sample and was diluted with deionized water, forming a solution of $100 \mathrm{~mL}$. A series of calcium standard solutions with concentrations of $0,1,2,3$, and $4 \mathrm{ppm}$ were made from the calcium stock of $1000 \mathrm{ppm}$. By using the AAS, the absorbance of the standards and samples were recorded. Total calcium content was analyzed using the standard curve of calcium.

Sodium

About $5 \mathrm{~mL}$ of potassium stock solution (prepared from $10 \%$ of potassium chloride solution) was added to the digested sample and diluted with deionized water to form a solution of $100 \mathrm{~mL}$. A series of sodium standard solutions with concentrations of $0,0.5,1.0,1.5$, and $2.0 \mathrm{ppm}$ were made from sodium stock of $1000 \mathrm{ppm}$. Total sodium content was analyzed using the standard curve of sodium.

Copper, Iron and Manganese

The digested sample was diluted with deionized water to form a solution of $100 \mathrm{~mL}$. A series of standard solutions were prepared for each mineral. For copper and iron standard solutions, concentrations of $0,1,2,3$, and $4 \mathrm{ppm}$ were made from copper stock of $1000 \mathrm{ppm}$ and iron stock of $1000 \mathrm{ppm}$. For manganese standard solutions, concentrations of $0,0.5,1.0,1.5$, and $2.0 \mathrm{ppm}$ were made from manganese stock of $1000 \mathrm{ppm}$. The total content of each mineral was analyzed using the standard curves prepared for each mineral.

\subsection{Statistical Analysis}

Data were analyzed using SPSS software, version 22 for Windows. All tests were conducted in triplicate, and mean values and standard deviations were reported. The differences between raw and dried samples were compared using an independent sample $t$-test at the level of significance of $p<0.05$.

\section{Results and Discussion}

\subsection{Analysis of Responses of Foaming Process}

The various combinations of independent variables generated by CCD of RSM are depicted in Table 3.

\subsubsection{Foam Density}

Foam density is commonly used to evaluate the whipping properties. The foam density displayed a low value when more air was incorporated into the foam during whipping. The presence of more air in the foam increases the whipping ability [24]. The foam density for the experiment of 20 runs varied, with values between $0.23 \mathrm{~g} / \mathrm{cm}^{3}$ and $0.49 \mathrm{~g} / \mathrm{cm}^{3}$. Foam density values in the range between $0.3 \mathrm{~g} / \mathrm{cm}^{3}$ and $0.6 \mathrm{~g} / \mathrm{cm}^{3}$ are suitable for the drying process of foam. The model $F$-value of 28.02, obtained from the statistical analysis, showed that the model was significant. There was only a $0.01 \%$ chance that a "Model F-Value" this large could occur due to noise. The coefficient of determination $\left(R^{2}\right)$ was also found to be significant (at $p<0.05$ ), exhibiting a value of 0.8820 . From the response surface plot (Figure 1), it can be seen that the concentration of egg albumen and methyl cellulose had a similar effect on the foam density. The foam density decreases when the concentration of egg albumen and methyl cellulose increase. However, a slight increase in foam density was found after a reduction in whipping time. High concentration of egg albumen causes a decrease in the foam density due to the 
reduction in the interfacial tension and surface tension of the liquid, forming an interfacial film. The slight increase in the foam density was due to bubble collapse when the whipping time increased [25].

Table 3. Experimental design for foam development from Nigella sativa solution with experimental value of responses.

\begin{tabular}{ccccccc}
\hline & \multicolumn{3}{c}{ Process Variables } & \multicolumn{3}{c}{ Responses } \\
\cline { 2 - 6 } Run No. & $\begin{array}{c}\text { \% Egg } \\
\text { Albumen }\end{array}$ & $\begin{array}{c}\text { \% Methyl } \\
\text { Cellulose }\end{array}$ & $\begin{array}{c}\text { Whipping } \\
\text { Time (min) }\end{array}$ & $\begin{array}{c}\text { Foam Density } \\
\left(\mathbf{g} / \mathbf{c m}^{3}\right)\end{array}$ & $\begin{array}{c}\text { Foam } \\
\text { Expansion (\%) }\end{array}$ & $\begin{array}{c}\text { Foam Stability } \\
\mathbf{( \% )}\end{array}$ \\
\hline 1 & 2.50 & 0.00 & 8 & 0.44 & 110 & 82.22 \\
2 & 8.75 & 0.50 & 5 & 0.35 & 244 & 85.95 \\
3 & 8.75 & 0.50 & 2 & 0.38 & 135 & 87.50 \\
4 & 2.50 & 0.00 & 2 & 0.49 & 45 & 71.00 \\
5 & 8.75 & 0.50 & 5 & 0.35 & 220 & 83.00 \\
6 & 15.00 & 0.00 & 2 & 0.35 & 105 & 85.71 \\
7 & 8.75 & 0.50 & 5 & 0.31 & 272 & 88.25 \\
8 & 2.50 & 1.00 & 2 & 0.40 & 144 & 72.49 \\
9 & 8.75 & 0.50 & 5 & 0.34 & 256 & 87.76 \\
10 & 15.00 & 1.00 & 2 & 0.38 & 169 & 98.70 \\
11 & 8.75 & 0.00 & 5 & 0.36 & 210 & 78.19 \\
12 & 2.50 & 0.50 & 5 & 0.37 & 233 & 95.24 \\
13 & 2.50 & 1.00 & 8 & 0.36 & 215 & 88.00 \\
14 & 8.75 & 0.50 & 5 & 0.29 & 266 & 87.91 \\
15 & 8.75 & 0.50 & 5 & 0.32 & 264 & 100.00 \\
16 & 15.00 & 1.00 & 8 & 0.36 & 252 & 94.68 \\
17 & 8.75 & 1.00 & 5 & 0.40 & 240 & 83.11 \\
18 & 15.00 & 0.00 & 8 & 0.23 & 328 & 93.27 \\
19 & 8.75 & 0.50 & 8 & 0.26 & 300 & 91.12 \\
20 & 15.00 & 0.50 & 5 & 0.27 & 308 & \\
\hline
\end{tabular}

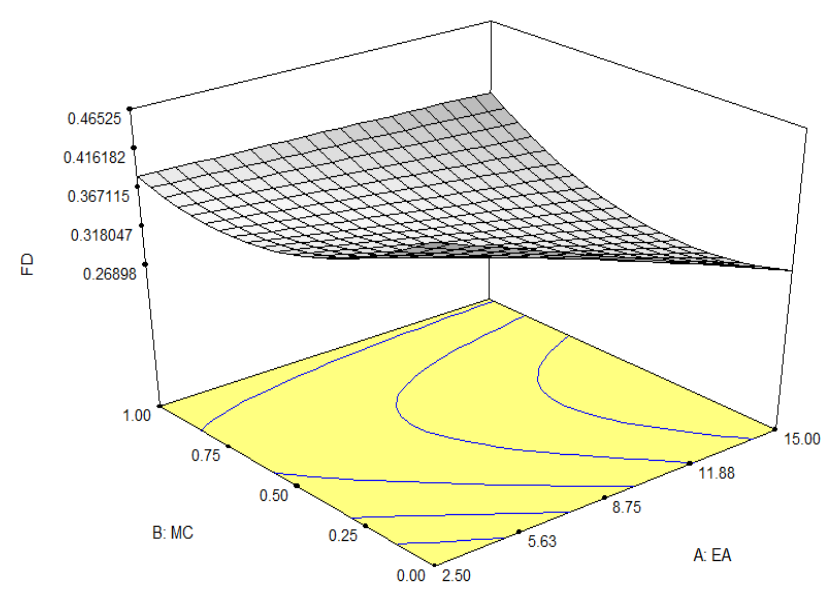

Figure 1. Effects of egg albumen (EA) and methyl cellulose (MC) on the foam density at a constant whipping time (5 $\mathrm{min})$.

\subsubsection{Foam Expansion}

Foam expansion is used to indicate the amount of air incorporated into the solution during the foaming process, and the increase in volume was measured as a percentage. Upon the application of various combinations, the foam expansion ranged from $45 \%$ to $328 \%$. A significant $F$-value of 19.52 was observed following statistical analysis. There was only a $0.01 \%$ chance that a "Model $F$-Value" this large could occur due to noise. In Table 4 , the coefficient of determination $\left(R^{2}\right)$, with a value of 0.9193 , indicates the significance of the results $(p<0.05)$. Figure 2 shows the effect of varying the concentration of egg albumen and methyl cellulose, but maintaining a constant whipping time of $5 \mathrm{~min}$, on the foam expansion. The foam expansion increases when the concentration of egg albumen 
and the concentration of methyl cellulose also increase. This is due to the proteins that are present in the foaming agent. During whipping, the proteins become denatured at the interphase, and interact with one another to form a stable interfacial film [26].

Table 4. Analysis of variance for the response surface quadratic model for foaming process.

\begin{tabular}{ccccccc}
\hline Response & $\begin{array}{c}\text { Sum of } \\
\text { Squares }\end{array}$ & $\begin{array}{c}\text { Degree of } \\
\text { Freedom }\end{array}$ & $\begin{array}{c}\text { Mean } \\
\text { Square }\end{array}$ & $\boldsymbol{F}$-Value & $\boldsymbol{p}$-Value & $\boldsymbol{R}^{\mathbf{2}}$ \\
\hline Foam Density & 0.062 & 4 & 0.015 & 28.02 & $<0.0001$ & 0.8820 \\
Foam Expansion & $98,685.61$ & 7 & $14,097.94$ & 19.52 & $<0.0001$ & 0.9193 \\
Foam Stability & 1080.58 & 6 & 180.10 & 29.60 & $<0.0001$ & 0.9318 \\
\hline
\end{tabular}

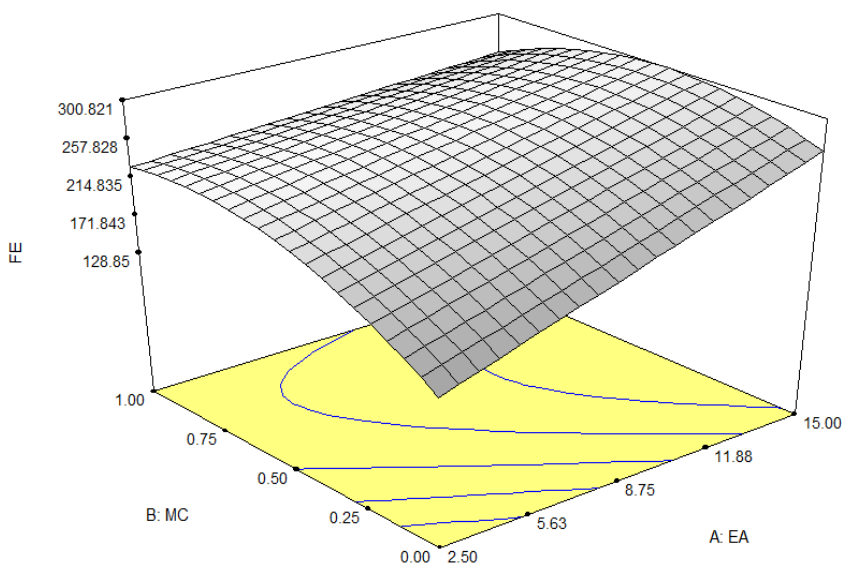

Figure 2. Effects of egg albumen (EA) and methyl cellulose (MC) on the foam expansion at a constant whipping time (5 $\mathrm{min})$.

\subsubsection{Foam Stability}

Foam stability determines how long the foam can extend, without liquid draining from the foam [27]. The foam stability ranged from $71 \%$ to $100 \%$. A higher percentage for the foam stability implies a higher water holding capacity of the foam. The model $F$-value of 29.60 , with a coefficient of regression $\left(R^{2}\right)$ of 0.9381 , showed that the model was significant $(p<0.05)$. Figure 3 illustrates that the foam stability increases when the concentration of egg albumen and methyl cellulose also increase. An increase in the concentration of methyl cellulose may reduce the surface tension, thus encouraging the formation of a strong film.

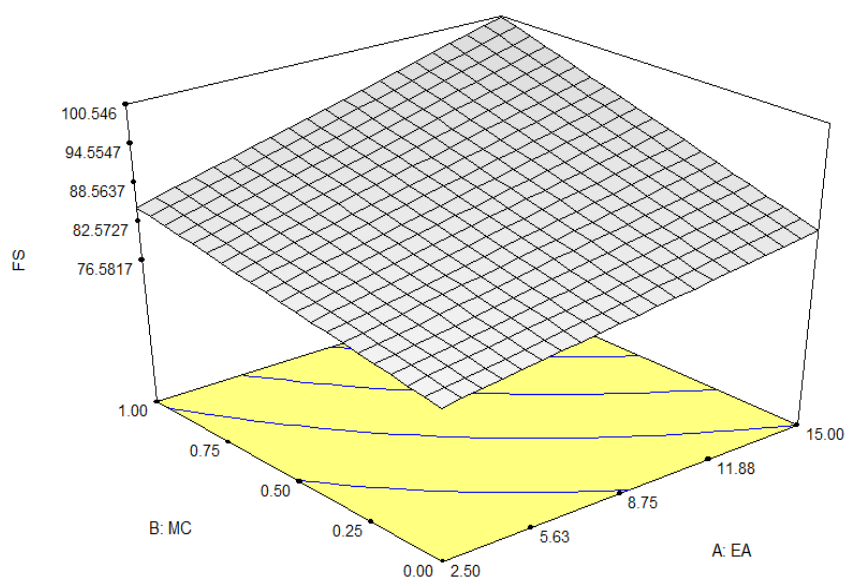

Figure 3. Effects of egg albumen (EA) and methyl cellulose (MC) on the foam stability at constant whipping time (5 $\mathrm{min})$. 


\subsubsection{Optimization of the Foaming Parameters}

The response of the foaming of the Nigella sativa solution were optimized to obtain minimum foam density, and maximum foam expansion and foam stability. Based on the desirability of the process variables, the best solution was selected for optimization, and the optimized foaming parameters were $15 \%$ of egg albumen, $0.69 \%$ of methyl cellulose, and 8 min of whipping time.

\subsection{Analysis of Responses of Drying Process}

From the results obtained in Table 5, the $a^{*}$ and $b^{*}$ results showed a low coefficient of determination, $R^{2}(0.3401$ and 0.3961 , respectively), and the models were not significant $(p>0.05)$. The effects of drying temperature and foam thickness on moisture content, water activity, water solubility and absorption index, colour $\left(L^{*}, a^{*}, b^{*}\right)$ values, and bulk and tapped density, are shown in Table 6 . The values of $a^{*}$ and $b^{*}$ variations between treatments were large, thus the model did not truly represent the data. This could be due to the range included in this study.

Table 5. Analysis of variance for the response surface quadratic model for drying process.

\begin{tabular}{|c|c|c|c|c|c|c|}
\hline Response & Sum of Squares & Degree of Freedom & Mean Square & $F$-Value & $p$-Value & $R^{2}$ \\
\hline Water activity & 0.025 & 3 & 0.008334 & 24.27 & 0.0001 & 0.8900 \\
\hline Water absorption index & 3.98 & 3 & 1.33 & 22.28 & 0.0002 & 0.8813 \\
\hline$L^{*}$ & 18.76 & 2 & 9.38 & 36.08 & $<0.0001$ & 0.8783 \\
\hline$a^{*}$ & 1.4 & 3 & 0.47 & 1.55 & 0.2689 & 0.3401 \\
\hline Bulk density & 0.006618 & 2 & 0.003309 & 16.21 & 0.0007 & 0.7643 \\
\hline Tapped density & 0.011 & 2 & 0.005688 & 10.59 & 0.0034 & 0.6793 \\
\hline
\end{tabular}

Table 6. Experimental design for foam mat dried Nigella sativa powder with experimental value of responses.

\begin{tabular}{|c|c|c|c|c|c|c|c|c|c|c|c|}
\hline \multirow[b]{2}{*}{$\begin{array}{c}\text { Run } \\
\text { No. }\end{array}$} & \multicolumn{2}{|c|}{ Process Variables } & \multicolumn{3}{|c|}{ Responses } & \multirow[b]{2}{*}{ WAI } & \multirow[b]{2}{*}{$L^{*}$} & \multirow[b]{2}{*}{$a^{*}$} & \multirow[b]{2}{*}{$b^{*}$} & \multirow{2}{*}{$\begin{array}{c}\text { Bulk } \\
\text { Density } \\
\left(\mathrm{g} / \mathrm{cm}^{3}\right)\end{array}$} & \multirow{2}{*}{$\begin{array}{l}\text { Tapped } \\
\text { Density } \\
\left(\mathrm{g} / \mathrm{cm}^{3}\right)\end{array}$} \\
\hline & $\begin{array}{c}\text { Temperature } \\
\left({ }^{\circ} \mathrm{C}\right)\end{array}$ & $\begin{array}{c}\text { Foam Thickness } \\
(\mathrm{mm})\end{array}$ & $\begin{array}{l}\text { MC } \\
(\%)\end{array}$ & Aw & $\begin{array}{l}\text { WSI } \\
(\%)\end{array}$ & & & & & & \\
\hline 1 & 70 & 1 & 5.61 & 0.32 & 55.45 & 3.218 & 34.38 & 12.84 & 21.72 & 0.263 & 0.334 \\
\hline 2 & 50 & 2 & 8.16 & 0.489 & 25.45 & 4.559 & 34.02 & 12.81 & 22.56 & 0.334 & 0.386 \\
\hline 3 & 60 & 2 & 7.65 & 0.451 & 45.69 & 3.825 & 37.06 & 12.79 & 23.47 & 0.335 & 0.359 \\
\hline 4 & 60 & 2 & 7.69 & 0.45 & 42.16 & 3.986 & 36.83 & 12.14 & 22.02 & 0.315 & 0.388 \\
\hline 5 & 60 & 1 & 6.88 & 0.414 & 45.95 & 4.126 & 35.35 & 13.03 & 22.71 & 0.315 & 0.36 \\
\hline 6 & 70 & 2 & 6.1 & 0.409 & 49.51 & 2.743 & 35.3 & 12.74 & 22.34 & 0.28 & 0.36 \\
\hline 7 & 60 & 3 & 7.5 & 0.466 & 47.18 & 3.328 & 36.85 & 11.82 & 21.66 & 0.359 & 0.457 \\
\hline 8 & 50 & 3 & 8.68 & 0.51 & 27.38 & 4.664 & 34.68 & 12.38 & 22.04 & 0.335 & 0.457 \\
\hline 9 & 60 & 2 & 7.78 & 0.473 & 46.36 & 4.147 & 37.07 & 11.89 & 22 & 0.313 & 0.358 \\
\hline 10 & 50 & 1 & 8.04 & 0.46 & 26.12 & 4.326 & 33.86 & 13.38 & 22.87 & 0.335 & 0.386 \\
\hline 11 & 60 & 2 & 7.53 & 0.461 & 45.69 & 3.825 & 37.22 & 11.3 & 21.17 & 0.314 & 0.386 \\
\hline 12 & 60 & 2 & 7.68 & 0.483 & 44.51 & 4.045 & 36.83 & 11.9 & 22 & 0.313 & 0.358 \\
\hline 13 & 70 & 3 & 5.78 & 0.482 & 48.02 & 2.839 & 34.22 & 12.29 & 21.06 & 0.28 & 0.36 \\
\hline
\end{tabular}

$\mathrm{MC}=$ moisture content; $\mathrm{Aw}=$ water activity; $\mathrm{WSI}=$ water solubility index; $\mathrm{WAI}$ = water absorption index.

\subsubsection{Moisture Content and Water Activity}

Moisture content and water activity are two of the most important parameters for producing a shelf-stable product, and they must be minimized during the processing. The range in moisture content and water activity for foam mat dried Nigella sativa powder, were $5.61 \%$ to $8.68 \%$ and 0.32 to 0.51 , respectively. For moisture content, the model $F$-value of 64.68 , with a coefficient of regression $\left(R^{2}\right)$ of 0.97 , showed that the model was significant (at $\left.p<0.05\right)$, whereas for water activity, the model $F$-value of 24.27, with a coefficient of regression $\left(R^{2}\right)$ of 0.8900 , showed that the model was significant 
$(p<0.05)$. Table 6 shows that, at a higher drying temperature, the moisture content and water activity decreased. A similar trend has been reported for foam mat dried yogurt powder [28].

\subsubsection{Water Solubility Index (WSI)}

The WSI measures the amount of soluble components released from the sample. The WSI ranged from $25.45 \%$ to $55.45 \%$. A model $F$-value of 108.54 , produced from the statistical analysis, inferred that the model was significant. The coefficient of determination $\left(R^{2}\right)$ was 0.9731 , so was also found to be significant (at $p<0.05$ ). Table 6 illustrates that the WSI increased as the drying temperature also increased. This is because a higher temperature resulted in powder with a higher porosity. Higher porosity led to a larger surface area of the powder, resulting in a larger surface contact area between the powder and water [29].

\subsubsection{Water Absorption Index (WAI)}

The WAI is an important parameter in terms of being able to reconstitute the powder in a liquid system. Upon the application of various combinations, the water absorption index ranged from 2.74 , to 4.66. A model $F$-value of 22.28 implies that the model is significant. For the model fitted, the coefficient of determination $\left(R^{2}=0.8813\right)$ indicates that the model was significant $(p<0.05)$. The response surface plot shows the effects of varying drying temperatures and foam thicknesses (Table 6). From the plot, it can be seen that increasing the drying temperature decreases the WAI, whereas an increase in foam thickness, also increases the water absorption.

\subsubsection{Colour ( $L^{*}$ Value)}

The colour of the powder was measured using a Minolta Spectrophotometer. The $L^{*}$ values indicate a measure of colour in the light-dark axis, which also indicates that the sample turned dark, as the $L^{*}$ value reduced. The variation in the Nigella sativa powder colour ( $L^{*}$ values), with respect to drying temperatures and foam thicknesses, is presented in Figure $4 . L^{*}$ values of Nigella sativa powder ranged from 33.86, to 37.22. In Table 5, it can be seen that the $F$-value of 36.08 is significant. The coefficient of determination $\left(R^{2}\right)$, which had a value of 0.8783 , was also found to be significant (at $p<0.05$ ). From Figure 4 , it can be seen that the $L^{*}$ value decreased as the drying temperature increased. It has been reported that a decrease in $L^{*}$ values may be due to the formation of brown pigment during drying [30].

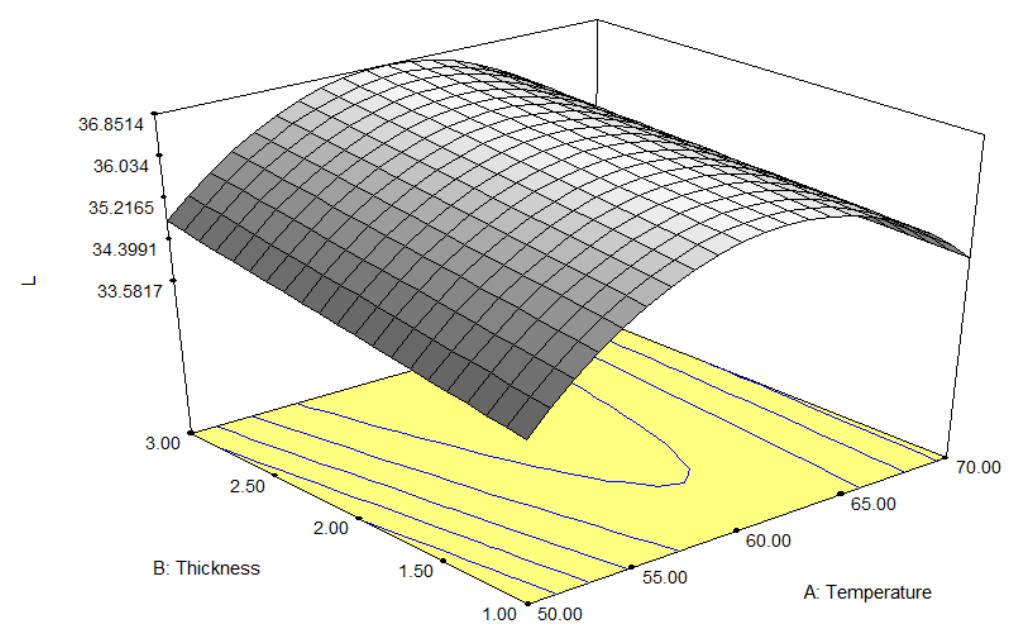

Figure 4. Effects of drying on the $L^{*}$ values of Nigella sativa powder. 


\subsubsection{Bulk and Tapped Density}

Density is one of the parameters that affects the functional properties of a powder. The bulk and tapped densities are important for the packing and arrangement of the particle, and the compaction profile of a material [30]. The bulk density of the Nigella sativa powder varied from 0.260 , to $0.340 \mathrm{~g} / \mathrm{cm}^{3}$, while the tapped density varied from 0.330 , to $0.440 \mathrm{~g} / \mathrm{cm}^{3}$. For bulk density, the model $F$-value was 16.21 , with a coefficient of regression $\left(R^{2}\right)$ of 0.7643 , whereas for tapped density, the model $F$-value was 10.59 , with a coefficient of regression $\left(R^{2}\right)$ of 0.6793 , illustrating that both of the models were significant (at $p<0.05$ ). At a higher temperature, the bulk and tapped densities decrease, as foam thickness also decreases (Table 6). The reduction in the density of the dried powder indicates rapid moisture removal at higher drying temperatures [26].

\subsubsection{Optimization of the Drying Parameters}

Following the development of models for various responses, the optimization of the process parameters were complete. From the various data obtained and by their statistical analysis, the criteria of process parameters were selected, such as the minimum value for moisture content, water activity, water solubility index, colour $\left(L^{*}, a^{*}, b^{*}\right.$ values), and bulk and tapped densities, while a high value for the water absorption index was used. Based on the desirability of the process variables, the best solution was selected for optimization, and the optimized drying parameters were $60^{\circ} \mathrm{C}$ for the drying temperature and $2 \mathrm{~mm}$ for the foam thickness.

\subsection{Quality of Nigella sativa Powder}

\subsubsection{Water Solubility Index}

Most food powders are intended for rehydration, meaning that the powder would become wet quickly and sink, rather than float. Besides, the powder can be easily dissolved or dispersed without the formation of lumps [31]. The water solubility index measures the number of soluble components released from the sample. As shown in Table 7, there was no significant difference $(p>0.05)$ between the roasted Nigella sativa, and the foam mat dried Nigella sativa powder. This can be explained by the addition of egg albumen to the Nigella sativa solution during the whipping process. During drying, the protein of the egg albumen may become denatured and coagulated, thus reducing the solubility of powder in water. This result shows that the solubility index of foam mat dried Nigella sativa powder is quite similar to that of roasted Nigella sativa. Research has shown that the water solubility index value increases when particle size decreases [32]. This is because there is larger surface contact between the water and powder. Thus, foam mat dried Nigella sativa powder had a higher solubility index because the particle size of the foam mat dried powder was finer than that of roasted Nigella sativa.

Table 7. The percentages inhibition of DPPH radical activity of the roasted Nigella sativa and the foam mat dried Nigella sativa powder.

\begin{tabular}{cccc}
\hline Samples & $\begin{array}{c}\text { Water Solubility } \\
\text { Index (\%) }\end{array}$ & $\begin{array}{c}\text { \% Inhibition of } \\
\text { DPPH }\end{array}$ & $\begin{array}{c}\text { Total Phenolic Content } \\
\text { (mg GAE/g) }\end{array}$ \\
\hline Roasted Nigella sativa & $46.03^{\mathrm{a}} \pm 1.33$ & $62.08^{\mathrm{a}} \pm 0.58$ & $26.769^{\mathrm{a}} \pm 1.33$ \\
Foam Mat Dried Nigella sativa Powder & $45.30^{\mathrm{a}} \pm 0.68$ & $56.60^{\mathrm{b}} \pm 0.39$ & $67.538^{\mathrm{b}} \pm 2.77$ \\
\hline
\end{tabular}

Mean \pm standard deviation $(n=3)$; Means within the different superscript letter were significantly different $(p<0.05)$.

\subsubsection{Antioxidant Activity}

The antioxidant activity of the roasted Nigella sativa and foam mat dried Nigella sativa powder was also studied, by evaluating the free radical-scavenging effect of the 2,2-diphenyl-1-picryl hydrazyl $(\mathrm{DPPH})$ radical. Determination of DPPH free radical-scavenging assay is based on the reduction of DPPH. DPPH is a stable free radical, even at room temperature. The free radical DPPH, with an odd 
electron, produces a maximum absorption rate at $515 \mathrm{~nm}$. When antioxidants react with DPPH, the stable free radical becomes paired off in the presence of a hydrogen donor, and is thus reduced. Table 7 shows the results for the percentage of inhibition of DPPH free radical activity of Nigella sativa powder and foam mat dried Nigella sativa powder. It demonstrates that there were significant differences in the percentage inhibition of DPPH free radical activity between the roasted Nigella sativa, and the foam mat dried Nigella sativa powder. The percentage of inhibition of DPPH free radical activity of foam mat dried powder was lower than that of roasted Nigella sativa. This result was in agreement with the finding of Liu et al. [33], who also reported that hot air drying caused a reduction in antioxidant activity, measured by the DPPH method. A lower percentage of DPPH scavenging is correlated with a lower antioxidant activity [34]. The reduction might be due to the lower scavenging activity exhibited by the dried powder, as a result of the drying process.

Drying exposes the sample to thermal treatment, which indirectly destroys the natural antioxidant found in that sample. However, the percentage of inhibition reduced to about $8.8 \%$. This may be due to the method of drying used for the experiment. Foam mat drying is a rapid drying process at lower temperatures. In addition, the percentages of inhibition of the roasted Nigella sativa and the foam mat Dried Nigella sativa powder, were high, displaying values of $62.08 \%$ and $56.50 \%$, respectively. This high percentage is due to the extraction method using $70 \%$ of methanol. Aqueous methanol (70\% methanol) is known to be an efficient and widely used solvent for extracting natural anti-oxidative components. It means that this solvent has the ability to extract maximum amounts of antioxidant components from the sample.

\subsubsection{Total Phenolic Content}

The total phenolic content was determined using the Folin-Ciocalteau method, expressed as the gallic acid equivalents. Phenolic content is important because most antioxidants are phenolic themselves. The highest phenolic value showed a high level of antioxidant activity. Previous studies have reported that the range of total phenolic content in Nigella sativa seed ranges from 12.1 to $78.8 \mathrm{mg}$ GAE/g [34,35]. As shown in Table 7, both the phenolic content of the roasted Nigella sativa and the foam mat dried Nigella sativa powder, were in the range of these reported values and there was a significant difference between the two samples. However, phenolic content in the foam mat dried Nigella sativa powder is higher than phenolic content in the roasted Nigella sativa. Theoretically, drying can cause some degradation in phenolic content. It has been stated that the total phenolic content can remain unchangeable, or even increase, after processing. An increase in phenol could be explained by the fact that the phenol compounds are easier to extract as a result of the structural alteration that takes place during the processing [36].

\subsubsection{Composition of Minerals}

The roasted Nigella sativa and the foam mat dried Nigella sativa powder were analyzed for the presence of elements of calcium, sodium, copper, iron, and manganese. Sultan et al. [37] reported that calcium, sodium, copper, iron, and manganese, were the common elements found in the Nigella sativa seed. The result of the mineral composition in the roasted Nigella sativa and the foam mat dried Nigella sativa powder, is listed in Table 8. Based on the result, the composition of calcium exhibited the highest value in both the roasted Nigella sativa and the foam mat dried Nigella sativa powder, with values of $6.626 \mathrm{mg} / \mathrm{kg}$ and $30.012 \mathrm{mg} / \mathrm{kg}$, respectively. This was in accordance with the previous study by Sultan et al. [37]. The second highest value is for sodium, followed by iron, manganese, and copper. The amount of iron, manganese, and copper in the foam mat dried Nigella sativa powder is lower than in the roasted Nigella sativa. The foam mat dried Nigella sativa powder consists of $0.258 \mathrm{mg} / \mathrm{kg}$ of iron, $0.012 \mathrm{mg} / \mathrm{kg}$ of manganese, and $0.057 \mathrm{mg} / \mathrm{kg}$ of copper, whereas the roasted Nigella sativa consist of $0.721 \mathrm{mg} / \mathrm{kg}$ of iron, $0.647 \mathrm{mg} / \mathrm{kg}$ of manganese, and $0.103 \mathrm{mg} / \mathrm{kg}$ of copper. This is because the foam mat dried Nigella sativa powder was exposed to the drying process. In general, drying can preserve food, due to moisture loss during the process, thus reducing the availability of water 
for microorganisms and enzymes. However, drying can also degrade some nutrients, such as trace minerals [37].

Table 8. Mineral content in the roasted Nigella sativa and the foam mat dried Nigella sativa powder.

\begin{tabular}{cccccc}
\hline Response & Ca & Na & Fe & Mn & Cu \\
\hline Roasted Nigella sativa & $6.626^{\mathrm{a}} \pm 0.27$ & $3.040^{\mathrm{a}} \pm 0.81$ & $0.721^{\mathrm{a}} \pm 0.01$ & $0.647^{\mathrm{a}} \pm 0.002$ & $0.103^{\mathrm{a}} \pm 0.006$ \\
$\begin{array}{c}\text { Foam Mat Dried } \\
\text { Nigella sativa Powder }\end{array}$ & $30.012^{\mathrm{b}} \pm 0.85$ & $3.538^{\mathrm{b}} \pm 0.10$ & $0.258^{\mathrm{b}} \pm 0.02$ & $0.012^{\mathrm{b}} \pm 0.002$ & $0.057^{\mathrm{b}} \pm 0.003$ \\
\hline
\end{tabular}

Mean \pm standard deviation $(n=3)$; Means within the different superscript letter were significantly different $(p<0.05)$.

In contrast, the amount of calcium and sodium in the foam mat dried Nigella sativa powder, with values of $30.012 \mathrm{mg} / \mathrm{kg}$ and $3.538 \mathrm{mg} / \mathrm{kg}$, respectively, were higher than in the roasted Nigella sativa, which had values of $6.626 \mathrm{mg} / \mathrm{kg}$ and $3.040 \mathrm{mg} / \mathrm{kg}$, respectively. The concentration of calcium and sodium of the foam mat dried Nigella sativa powder was found to be higher than in the roasted Nigella sativa. The result indicates that there was an increase in the calcium and sodium content after the foaming and drying process. The reason for this may be due to the high concentration of egg albumen in the formulation. This is because the egg albumen itself contains about $4.0 \mathrm{mg}$ of calcium and $53.0 \mathrm{mg}$ of sodium [35]. Another possible reason is the process of making egg albumen powder. The egg albumen used in this study is the commercial type, and thus there is the possibility that the egg albumen was mixed with other ingredients or underwent some processing, thus resulting in the higher calcium and sodium content in the foam mat dried Nigella sativa powder.

\section{Conclusions}

This study determined the physical and chemical properties of the instant powder, as well as the optimal parameters for its foam mat drying production. The response surface methodology was a useful tool for identifying the optimum parameters for the foaming and drying process when producing foam mat dried Nigella sativa powder. Using the central composite design of experiments, the optimized values were reported to be $15 \%$ of egg albumen, $0.69 \%$ of methyl cellulose, and 8 min of whipping time for the foaming process, and $60^{\circ} \mathrm{C}$ of drying temperature and $2 \mathrm{~mm}$ of foam thickness for the drying process.

In addition, the quality of the roasted Nigella sativa and foam mat dried Nigella sativa powder were compared in terms of solubility index, antioxidant activity, total phenolic content, and mineral content. The results show that there were significant differences in the percentage inhibition of DPPH, total phenolic content, and mineral content, but that there was no significant difference in the water solubility index of the roasted Nigella sativa and the foam mat dried Nigella sativa powder.

Besides, the foam mat dried Nigella sativa powder diplays a high percentage inhibition of DPPH, total phenolic content, and calcium and sodium content, although the solubility of the powder was not $100 \%$. From the study, it can be concluded that foam mat dried Nigella sativa powder can be used to produce healthy beverage powder, due to its nutritional quality. Further study can be pursued, regarding solubility, chemical stability, and microbial safety.

Author Contributions: Affandi, N. carried out the experimental work, handled and collected raw data and wrote the descriptive paper; Zzaman, W. analyzed and interpreted the data, participated in manuscript preparation and acted as corresponding author; Yang, T.A. and Easa, A.M. conceptualized the project, facilitated data collection and directed the whole research work.

Conflicts of Interest: The authors declare no conflict of interest.

\section{References}

1. Fumagalli, F.; Silveira, A.M. Quality evaluation of microwave-dried Packham's triumph pear. Dry. Technol. 2005, 23, 2215-2226. [CrossRef] 
2. Hertzendorf, M.S.; Moshy, R.J.; Seltzer, E. Foam mat drying in the food industry. Crit. Rev. Food Technol. 1970, 1, 25-70. [CrossRef]

3. Hsu, C.-L.; Chen, W.; Weng, Y.-M.; Tseng, C.-Y. Chemical composition, physical properties, and antioxidant activities of yams flours as affected by different drying methods. Food Chem. 2003, 83, 85-92. [CrossRef]

4. Ratti, C. Hot air and freeze-drying of high-value foods: A review. J. Food Eng. 2001, 49, 311-319. [CrossRef]

5. Nindo, C.I.; Tang, J. Refractance window dehydration technology: A novel contact drying method. Dry. Technol. 2007, 25, 37-48. [CrossRef]

6. Hasanah, H.; Chong, G.-L.; Suzana, S. Comparison of physicochemical analysis and antioxidant activities of Nigella sativa seeds and oils from Yemen, Iran and Malaysia. J. Sci. 2014, 43, 535-542.

7. Chandrasekar, V.; Gabriela, J.; Kannan, K.; Sangamithra, A. Effect of foaming agent concentration and drying temperature on physicochemical and antimicrobial properties of foam mat dried powder. Asian J. Dairy Food Res. 2015, 34, 39-43. [CrossRef]

8. Kadam, D.M.; Wilson, R.A.; Kaur, S. Determination of biochemical properties of foam-mat dried mango powder. Int. J. Food Sci. Technol. 2010, 45, 1626-1632. [CrossRef]

9. Rajkumar, P.; Kailappan, R.; Viswanathan, R.; Raghavan, G.; Ratti, C. Foam mat drying of Alphonso mango pulp. Dry. Technol. 2007, 25, 357-365. [CrossRef]

10. Kandasamy, P.; Varadharaju, N.; Kalemullah, S.; Moitra, R. Production of papaya powder under foam-mat drying using methyl cellulose as foaming agent. Asian J. Food Agro-Ind. 2012, 5, 374-387.

11. Krasaekoopt, W.; Bhatia, S. Production of yogurt powder using foam-mat drying. AU J. Technol. 2012, 15, 166-171.

12. Sankat, C.K.; Castaigne, F. Foaming and drying behaviour of ripe bananas. LWT-Food Sci. Technol. 2004, 37, 517-525. [CrossRef]

13. Karim, A.A.; Wai, C.C. Foam-Mat drying of starfruit (Averrhoa carambola L.) puree. Stability and air drying characteristics. Food Chem. 1999, 64, 337-343. [CrossRef]

14. Kato, A.; Takahashi, A.; Matsudomi, N.; Kobayashi, K. Determination of foaming properties of proteins by conductivity measurements. J. Food Sci. 1983, 48, 62-65. [CrossRef]

15. Marinova, K.G.; Basheva, E.S.; Nenova, B.; Temelska, M.; Mirarefi, A.Y.; Campbell, B.; Ivanov, I.B. Physico-Chemical factors controlling the foamability and foam stability of milk proteins: Sodium caseinate and whey protein concentrates. Food Hydrocoll. 2009, 23, 1864-1876. [CrossRef]

16. Jittanit, W.; Niti-Att, S.; Techanuntachaikul, O. Study of spray drying of pineapple juice using maltodextrin as an adjunct. Chiang Mai J. Sci. 2010, 37, 498-506.

17. Grabowski, J.; Truong, V.D.; Daubert, C. Spray-Drying of amylase hydrolyzed sweetpotato puree and physicochemical properties of powder. J. Food Sci. 2006, 71, E209-E217. [CrossRef]

18. Chegini, G.; Ghobadian, B. Effect of spray-drying conditions on physical properties of orange juice powder. Dry. Technol. 2005, 23, 657-668. [CrossRef]

19. Patil, V.; Chauhan, A.K.; Singh, R.P. Optimization of the spray-drying process for developing guava powder using response surface methodology. Powder Technol. 2014, 253, 230-236. [CrossRef]

20. Kubola, J.; Siriamornpun, S. Phytochemicals and antioxidant activity of different fruit fractions (peel, pulp, aril and seed) of Thai gac (Momordica cochinchinensis Spreng). Food Chem. 2011, 127, 1138-1145. [CrossRef] [PubMed]

21. Thaipong, K.; Boonprakob, U.; Crosby, K.; Cisneros-Zevallos, L.; Byrne, D.H. Comparison of ABTS, DPPH, FRAP, and ORAC assays for estimating antioxidant activity from guava fruit extracts. J. Food Compos. Anal. 2006, 19, 669-675. [CrossRef]

22. Negro, C.; Tommasi, L.; Miceli, A. Phenolic compounds and antioxidant activity from red grape marc extracts. Bioresour. Technol. 2003, 87, 41-44. [CrossRef]

23. Ramesh, M.; Orsat, V. Spray drying for the production of nutraceutical ingredients-A review. Food Bioprocess Technol. 2012, 5, 3-14.

24. Falade, K.O.; Adeyanju, K.I.; Uzo-Peters, P.I. Foam-Mat drying of cowpea (Vigna unguiculata) using glyceryl monostearate and egg albumin as foaming agents. Eur. Food Res. Technol. 2003, 217, 486-491. [CrossRef]

25. Kudra, T.; Ratti, C. Foam-Mat drying: Energy and cost analyses. Can. Biosyst. Eng. 2006, 48, 3.

26. Thuwapanichayanan, R.; Prachayawarakorn, S.; Soponronnarit, S. Effects of foaming agents and foam density on drying characteristics and textural property of banana foams. LWT-Food Sci. Technol. 2012, 47, 348-357. [CrossRef] 
27. Kampf, N.; Martinez, C.G.; Corradini, M.G.; Peleg, M. Effect of two gums on the development, rheological properties and stability of egg albumen foams. Rheol. Acta 2003, 42, 259-268.

28. Karabulut, I.; Topcu, A.; Duran, A.; Turan, S.; Ozturk, B. Effect of hot air drying and sun drying on color values and $\beta$-carotene content of apricot (Prunus armenica L.). LWT-Food Sci. Technol. 2007, 40, 753-758. [CrossRef]

29. Chun, K.P.; Nazimah, S.A.H.; Chin, P.T.; Mirhosseini, H.; Russly, A.R.; Gulam, R. Optimization of drum drying processing parameters for production of jackfruit (Artocarpus heterophyllus) powder using response surface methodology. LWT-Food Sci. Technol. 2010, 43, 343-349.

30. Singh, A.K.; Selvam, R.P.; Sivakumar, T. Isolation, characterisation and formulation properties of a new plant gum obtained from mangifera indica. Int. J. Pharm. Biomed. Res. 2010, 1, 35-41.

31. Hogekamp, S.; Schubert, H. Rehydration of food powders. Food Sci. Technol. Int. 2003, 9, 223-235. [CrossRef]

32. Zhao, X.; Yang, Z.; Gai, G.; Yang, Y. Effect of superfine grinding on properties of ginger powder. J. Food Eng. 2009, 91, 217-222. [CrossRef]

33. Liu, H.; Qiu, N.; Ding, H.; Yao, R. Polyphenols contents and antioxidant capacity of 68 Chinese herbals suitable for medical or food uses. Food Res. Int. 2008, 41, 363-370. [CrossRef]

34. Nurhanani, R.; Rasyidah, R.; Sarni, M.; Azlina, A. Radical scavenging and reducing properties of extracts of cashew shoots (Anacardium occidentale). Food Chem. 2008, 111, 38-44.

35. Erkan, N.; Ayranci, G.; Ayranci, E. Antioxidant activities of rosemary (Rosmarinus officinalis L.) extract, blackseed (Nigella sativa L.) essential oil, carnosic acid, rosmarinic acid and sesamol. Food Chem. 2008, 110, 76-82. [CrossRef] [PubMed]

36. Williamson, G.; Carughi, A. Polyphenol content and health benefits of raisins. Nutr. Res. 2010, 30, 511-519. [CrossRef] [PubMed]

37. Sultan, M.T.; Butt, M.S.; Anjum, F.M.; Jamil, A.; Akhtar, S.; Nasir, M. Nutritional profile of indigenous cultivar of black cumin seeds and antioxidant potential of its fixed and essential oil. Pak. J. Bot. 2009, 41, 1321-1330.

(C) 2017 by the authors; licensee MDPI, Basel, Switzerland. This article is an open access article distributed under the terms and conditions of the Creative Commons Attribution (CC BY) license (http:/ / creativecommons.org/licenses/by/4.0/). 